\title{
Comorbidities and Concomitant Medication Use in Men with Prostate Cancer or High Levels of PSA Compared to Matched Controls: A GPRD Analysis
}

\author{
Haojie Li, ${ }^{1}$ Elizabeth Hodgson, ${ }^{2}$ Louise Watson, ${ }^{3}$ Amit Shukla, ${ }^{1}$ and Jeanenne J. Nelson ${ }^{2}$ \\ ${ }^{1}$ Quantitative Sciences Division, Worldwide Epidemiology, Research and Development, GlaxoSmithKline, Collegeville, PA 19426, USA \\ ${ }^{2}$ Quantitative Sciences Division, Worldwide Epidemiology, Research and Development, GlaxoSmithKline, Research Triangle Park, \\ NC 27709, USA \\ ${ }^{3}$ WREN Group, EPIPharmaCo Ltd., Buxton, UK
}

Correspondence should be addressed to Haojie Li, haojie.x.li@gsk.com

Received 4 November 2011; Revised 2 February 2012; Accepted 2 February 2012

Academic Editor: Emanuela Taioli

Copyright ( $) 2012$ Haojie Li et al. This is an open access article distributed under the Creative Commons Attribution License, which permits unrestricted use, distribution, and reproduction in any medium, provided the original work is properly cited.

\begin{abstract}
Comorbidity influences screening practice, treatment choice, quality of life, and survival. The presence of comorbidities and medication use could place patients at greater risks of adverse effects from certain interventions. We conducted a longitudinal cohort study in the General Practice Research Database to better understand comorbidities and medication use in men with or at risk of prostate cancer $(\mathrm{CaP})$. Compared with men with similar age but no $\mathrm{CaP}, \mathrm{CaP}$ patients had higher incidence of urinary tract infection, impotence and breast disorder, and 2.6-fold higher all-cause mortality. Among men with elevated prostate-specific antigen (PSA) but no CaP, the mortality rates were slightly lower, and fewer differences in comorbidities and medication use were noted compared to men without elevated PSA. Many prevalent comorbidities and medications were consistent across groups and are typical of an older male population. These real-world data are broadly applicable throughout the drug development cycle and subsequent patient management.
\end{abstract}

\section{Introduction}

Prostate cancer $(\mathrm{CaP})$ is the most common nonskin cancer and the second or third leading cause of death from cancer among men in the developed world [1]. In the UK, more than 36,000 men are diagnosed with $\mathrm{CaP}$ each year, comprising a quarter of all cancers diagnosed in men. Although approximately 10,000 men died from CaP in the UK in 2008, survival rates for $\mathrm{CaP}$ patients have changed markedly over the past 40 years. More than $75 \%$ of $\mathrm{CaP}$ patients currently survive beyond five years, compared with less than a third of the patients with five-year survival in the 1970s; the differential is even greater in the ten-year survival experiences now compared to 40 years ago [2]. Thus, the CaP patient population is large. Moreover, in this large group, the burden of disease from $\mathrm{CaP}$ is preponderantl in elderly men, with men who are 70 years or older comprising more than half the patient population in the UK.
Consequently, CaP patients often present for medical care with advanced age-related comorbidities [3]. The number and types of patient comorbidities have informed treatment choice for $\mathrm{CaP}$ in clinical practice, with less aggressive treatment used as comorbidity increases [4-9]. Comorbidity scores have been shown to predict outcomes ranging from late urinary complications [10] to overall survival [11] among men who have undergone radical prostatectomy. Moreover, specific comorbidities, or a high number of comorbidities, have been used in some instances to exclude patients from clinical trials due to concerns of increased risk of adverse events [12]. Therefore, a thorough understanding of the occurrence of comorbidities in $\mathrm{CaP}$ patients in a realworld setting has important implications for drug development, clinical practice, and patient management.

While there has been excellent work to date documenting the impact of comorbidities on treatment decisions among 
men with $\mathrm{CaP}$, these studies have some limitations from the perspective of clinical development of novel treatment or preventive medicines. Many studies examined the existence of the comorbidity only at the time of initial $\mathrm{CaP}$ diagnosis. There is sparse information that describes comorbid illnesses that arise during the treatment phase of the disease. Moreover, several studies restricted comorbid information to scores for the intent of profiling the overall "risk" of each patient, rather than examining specific comorbidities. Additionally, only one study reported to date has compared $\mathrm{CaP}$ patients to an age-similar non-CaP group. Quantification of specific concomitant diseases during a prevention or treatment period in a population of patients that closely mirror users of novel therapies and putting these rates in context with rates from age-similar populations is useful.

Therefore, to complement the body of information from previous studies, we conducted a longitudinal cohort study in the General Practice Research Database (GPRD) among men with $\mathrm{CaP}$ and compared specific comorbidities and medications among these men to an age-, practice-, and length of followup-matched set of controls. In addition to prevalence of comorbidities at the time of initial cancer diagnosis, we examined the incidence of major comorbidities during a follow-up period of approximately four years and overall survival for the entire observation period in both cases and controls. We further defined a cohort of men at risk for $\mathrm{CaP}$, demonstrated by 2 or more elevations in PSA level within 12 months, but without $\mathrm{CaP}$, and matched this high-risk group to a noncancer, non-PSA-elevated control population to explore background prevalence, incidence, and medication use rates as a framework for better understanding patients in one of our major on-going clinical development programs.

\section{Objectives}

The objective of this study was to compare the prevalence and incidence of comorbidities and concomitant medication use and overall survival in patients with $\mathrm{CaP}$ and in men at risk of $\mathrm{CaP}$, defined as having prostate-specific antigen (PSA) levels $>2.5 \mathrm{ng} / \mathrm{mL}$ but without $\mathrm{CaP}$, to men of the same age without $\mathrm{CaP}$ and no elevated PSA. Comorbidities or newly occurring events of specific interest included urinary tract infections (UTI), impotence, breast disorders, hypertension, acute coronary syndrome, myocardial infarction, angina pectoris, stroke, congestive heart failure, cardiac arrhythmias, lower extremity arterial occlusive disease, type II diabetes, and hyperlipidemia, conditions selected for their relevance to the age group and to reported events among men with or at risk of CaP.

\section{Materials and Methods}

The study was a retrospective longitudinal comparative cohort study of men in the GPRD, comprising data from August 1, 1998 to July 31, 2008. We obtained institutional review board (IRB) approval for conducting this study. The GPRD is a population-based electronic medical records database in the UK. Data are drawn from the computer systems used by general practitioners (GPs) to maintain clinical records within their practices and contain all primary care records deemed relevant to patient care. Data quality is monitored continuously by the UK Medicines and Healthcare products Regulatory Agency (MHRA), and practices that fail to maintain the required standards are removed from the database. Currently, data are collected from 613 general practices throughout the UK, providing information from 9.7 million patients with records in the system at any time point and 4.5 million currently registered patients. Mean follow-up is 6.6 years (median, 5.0 years) for currently registered patients.

3.1. Study Population. Among men $\geq 18$ years of age in the GPRD, we identified two cohorts of men, referred to as "cases": men with a diagnostic code of CaP who had no record of cancers other than $\mathrm{CaP}$ and nonmelanoma skin cancer and men with at least two elevated PSA results, defined as PSA > $2.5 \mathrm{ng} / \mathrm{mL}$, but no diagnosis of CaP. Given that there is a continuum of CaP risk at all values of PSA and no cutpoint of PSA with simultaneous high sensitivity and high specificity for identifying CaP [13], PSA $>2.5 \mathrm{ng} / \mathrm{mL}$ was selected to be consistent with the inclusion criteria in a major on-going clinical trial. A man with elevated PSA who went on to have $\mathrm{CaP}$ was included only in the $\mathrm{CaP}$ group. The date of the first $\mathrm{CaP}$ diagnosis was the index date for each $\mathrm{CaP}$ patient, and the date when the first elevated PSA result was recorded was the index date for each man with elevated PSA but no CaP. A second elevated PSA result must have been recorded within 12 months after the index date to ensure a true positive result, as patients may have had a false positive reading or may have had elevated levels due to acute urinary tract infection.

For each case, a control was selected among those who had no diagnostic codes for $\mathrm{CaP}$, no benign prostate conditions, that is, benign prostatic hyperplasia (BPH) and/or prostatitis, and no elevated PSA result, but had at least one PSA measurement throughout the 10-year observation period. Cases could, however, have a diagnosis of prostatitis or $\mathrm{BPH}$ at any time. Cases and controls were matched on age $( \pm 1$ year when possible, up to \pm 5 years allowed), region of practice, length of follow-up, and observation period (either August 1, 1998 to July 31, 2003 or August 1, 2003 to July $31,2008)$. Matching on region of practice was to ensure similar socioeconomic factors, such as income and access to health insurance or scored utilization of primary health care, between cases and controls. Replacements were not allowed. The index date for each control was the same as the index date of his matched case.

We included only those men that had at least 12-month history in the GPRD prior to the index date in order to adequately assess prior occurrences of disease or event of interest. Men must have had at least 3 months of follow-up postindex date to be included in the postindex date analysis of prevalent comorbidities and medications. No minimum follow-up was required for analysis of incident comorbidities and medications, which allowed inclusion of less healthy (e.g., near terminal) CaP patients, resulting in a more generalizable $\mathrm{CaP}$ population. For medication use, we restricted 
our population to the subgroup of men with index dates between August 1, 2003 and July 31, 2008, in order to provide a more up-to-date pattern for medication use.

Baseline characteristics included age at the index date, region of practice (defined as Eastern, Southern, Northern London, and others), smoking status (defined as never, current, and past), and PSA levels. PSA levels were categorized as $\leq 2.5,2.51-10$, and $>10 \mathrm{ng} / \mathrm{mL}$. They were also categorized by the age-dependent UK cutoff values of $\geq 3.0 \mathrm{ng} / \mathrm{mL}$ for men aged $50-59$ years, $\geq 4.0 \mathrm{ng} / \mathrm{mL}$ for men aged $60-69$ years, and $>5.0 \mathrm{ng} / \mathrm{mL}$ for men aged 70 years and over, as recommended by the Prostate Cancer Risk Management Programme [14].

3.2. Study Outcomes. Diseases and events of specific interest included UTI, impotence, breast disorders, hypertension, acute coronary syndrome, myocardial infarction, angina pectoris, stroke, congestive heart failure, cardiac arrhythmias, lower extremity arterial occlusive disease, type II diabetes, and hyperlipidemia and were defined according to the READ and OXMIS Codes. General comorbidities were examined among the entire cohort of men, listed by the MedDRA highlevel terms. Medications were assessed among a subgroup of men in GPRD within the latter five years (i.e., index dates between August 1, 2003 and July 31, 2008), listed by class per British National Formulary (BNF) header within the product files. Patient mortality status (yes/no) was used for calculating the all-cause mortality rates. Causes of death were obtained for approximately $60 \%$ of patients in GPRD, those who had consented to the linkage to the Office for National Statistics (ONS) death data. The underlying causes of death were recorded and described according to the International Statistical Classification of Diseases and Related Health Problems 10th Revision (ICD-10) [15]. Frequencies of more than $2 \%$ for individual events and of more than $3 \%$ for systems of diseases were reported.

3.3. Statistical Analysis. We compared baseline characteristics in the two case groups that were successfully control matched to the cases we were unable to match. Within each matched set, we compared baseline characteristics of each case group to its respective control group.

For comorbidities of special interest, we examined the prevalence during the 12 months prior to the index date and the cumulative incidence for the entire follow-up period. Cumulative incidence analysis was conducted among the atrisk population comprising only men who did not have a documented specific comorbid event during the 12-month period prior to the index date. Men who left the GPRD data system during follow-up due to sustained inactivity (no record of any diagnosis or medication during 12 months), known transfer out of the system, or death were included in the at-risk denominator. We evaluated the incidence rates, in person-years (PY), at 12 and 48 months of follow-up, and explored the trend between the two periods. The incidence rate calculation accounts for varying degrees of follow-up, with PY calculated as the time interval between the index date and either the date of the event, the date when they became inactive, the date they were transferred out of the
GPRD system, the date of death, or July 31, 2008, whichever came first.

For capturing the most frequently occurring comorbidities and concomitant medication use, we examined the prevalence over the 12 months prior to the index date (preperiod) as well as 12 months after the index date (postperiod). We compared the prevalence among cases versus controls within each period and then the prevalence during the pre-period versus the post-period within each group.

Kaplan-Meier survival curves were plotted, and all-cause mortality rates were estimated for men with $\mathrm{CaP}$, men with elevated PSA but no CaP, and their matched controls over the 10-year period.

All analyses were conducted using SAS version 9.1.3, with a significance level of $\alpha=0.05$. For each comorbidity and concomitant medication, the significance of the prevalence or cumulative incidence comparison between cases and controls was tested by a two-sided Fisher's exact test of the null hypothesis odds ratio, $\mathrm{OR}=1$ (i.e., odds in cases $=$ odds in controls). For incidence rate or mortality rate comparisons, a two-sided significance test was performed on the null hypothesis rate ratio, $\mathrm{RR}=1$ (i.e., rate in cases $=$ rate in controls). This was based on the assumption that the counts have Poisson distributions, so that the distribution of $\log (\mathrm{RR})$ is approximately Normal, a valid assumption provided that case and control counts are fairly large $(>30)$. The formula for the variance of a $\log (\mathrm{RR})$ given, for example, by Agresti (p. 71) [16] can then be adapted to obtain $\operatorname{var}(\log (\mathrm{RR}))=1 / n_{1}+1 / n_{2}$, where $n_{1}=$ count in cases and $n_{2}=$ count in controls. The estimate of $\log (\mathrm{RR})$ and its variance are then used to perform a $z$ test of the null hypothesis. Neither test takes account of the pairing of cases and controls and is therefore conservative. No adjustment was made for multiple comparisons.

\section{Results}

4.1. Baseline Characteristics. In the GPRD, 3,036 CaP patients and 11,339 men with elevated PSA but no CaP were identified. Of these, matching was successful for $86 \%$ of the $\mathrm{CaP}$ patients and $89 \%$ of those with elevated PSA but no $\mathrm{CaP}$. Unmatched cases (420 CaP patients and 1,211 men with elevated PSA but no $\mathrm{CaP}$ ) were older than the matched cases (median age 81 years versus 68 or 72 years, resp.) and had a greater proportion with PSA of $>10 \mathrm{mg} / \mathrm{mL}$ (35\% versus $20 \%$, resp.).

$\mathrm{CaP}$ patients were slightly older than men with elevated PSA but no CaP, with median ages of 72 and 68 years, respectively (Table 1). In both case groups, nearly half of the men were nonsmokers and 13-16\% were current smokers. Among men with elevated PSA but no CaP, $19.7 \%$ had PSA levels over $10 \mathrm{ng} / \mathrm{mL}$; using age-specific UK cutoff values, as per National Health Service guidance, only $75 \%$ of these men would have been classified as having elevated PSA.

4.2. Prevalence and Incidence of Specific Comorbidities of Interest. During the 12 months prior to the index date, $28 \%$ of the CaP patients had $\mathrm{BPH}$ and $2 \%$ had prostatitis. Among men with elevated PSA but no CaP, $13 \%$ had BPH and $0.8 \%$ 
TABLE 1: Baseline characteristics among prostate cancer patients, men with elevated PSA levels but no CaP, and their matched controls in the General Practice Research Database (GPRD, 1998-2008).

\begin{tabular}{|c|c|c|c|c|}
\hline \multirow[t]{2}{*}{ Study population } & \multicolumn{2}{|c|}{$\begin{array}{c}\text { Prostate cancer patients (cases) and } \\
\text { matched controls }\end{array}$} & \multicolumn{2}{|c|}{$\begin{array}{l}\text { Men with elevated PSA but no CaP (cases) and } \\
\text { matched controls }\end{array}$} \\
\hline & Cases & Controls & Cases & Controls \\
\hline$N$ & 2,616 & 2,616 & 10,128 & 10,128 \\
\hline Mean age $^{1}$, year $(S D)$ & \multicolumn{2}{|c|}{$72(9)$} & \multicolumn{2}{|c|}{$68(9)$} \\
\hline \multicolumn{5}{|l|}{ Region $^{1}(\%)$} \\
\hline Eastern & \multicolumn{2}{|c|}{$15 \%$} & \multicolumn{2}{|c|}{$14 \%$} \\
\hline Southern & \multicolumn{2}{|c|}{$36 \%$} & \multicolumn{2}{|c|}{$38 \%$} \\
\hline Northern & \multicolumn{2}{|c|}{$30 \%$} & \multicolumn{2}{|c|}{$28 \%$} \\
\hline London & \multicolumn{2}{|c|}{$10 \%$} & \multicolumn{2}{|c|}{$9 \%$} \\
\hline Others $^{2}$ & \multicolumn{2}{|c|}{$9 \%$} & \multicolumn{2}{|c|}{$11 \%$} \\
\hline \multicolumn{5}{|l|}{ Smoking $^{3}(\%)$} \\
\hline Never & $49 \%$ & $46 \%$ & $47 \%$ & $41 \%$ \\
\hline Current & $13 \%$ & $15 \%$ & $12 \%$ & $16 \%$ \\
\hline Past & $38 \%$ & $39 \%$ & $41 \%$ & $43 \%$ \\
\hline \multicolumn{5}{|l|}{ PSA $^{3}(\%)$} \\
\hline$\leq 2.5 \mathrm{ng} / \mathrm{mL}$ & $3.5 \%$ & $100.0 \%$ & $0.0 \%$ & $100.0 \%$ \\
\hline $2.51-10 \mathrm{ng} / \mathrm{mL}$ & $29.5 \%$ & - & $80.3 \%$ & - \\
\hline$>10 \mathrm{ng} / \mathrm{mL}$ & $67.0 \%$ & - & $19.7 \%$ & - \\
\hline Elevated $^{4}$ & $93.9 \%$ & - & $74.9 \%$ & - \\
\hline Not elevated & $6.1 \%$ & $100.0 \%$ & $25.1 \%$ & $100.0 \%$ \\
\hline
\end{tabular}

${ }^{1}$ Matching factors.

${ }^{2}$ Northern Ireland, Scotland, Wales.

${ }^{3}$ Data on smoking status were missing for $168 \mathrm{CaP}$ patients, $205 \mathrm{CaP}$ controls, 511 men with elevated PSA, and 562 controls for elevated PSA; PSA data were missing for $1285 \mathrm{CaP}$ patients.

${ }^{4}$ Based on UK cutoffs, $\geq 3.0$ among those with age $50-59$ years; $\geq 4.0$ among those with age $60-69$ years; $>5.0$ among those with age 70 and over.

had prostatitis (data not shown). No controls had these diagnoses per study design. In both case groups, men had a 3- to 5-fold higher prevalence of UTIs and somewhat higher prevalence of impotence compared with controls (Table 2). Men with elevated PSA but no CaP had a lower prevalence of diabetes than their controls.

The cumulative incidence of UTI was also significantly higher, and the cumulative incidence of stroke was lower in each case group compared to their matched controls (Table 3). Compared with controls, CaP patients also had higher cumulative incidence of impotence and breast disorder and lower cumulative incidence of hyperlipidemia. Men with elevated PSA but no CaP had lower cumulative incidence of congestive heart failure. No differences between cases and controls were observed for hypertension, acute coronary syndrome, angina pectoris, myocardial infarction, Type II diabetes, and lower extremity arterial disease.

Incidence rates per 10,000 person-years, which account for varying follow-up time, demonstrated statistically significant differences between $\mathrm{CaP}$ cases and controls for the outcomes of UTI, impotence, and breast disorder. Specifically, $\mathrm{CaP}$ patients had a nearly 5 -fold higher incidence rate (IR) of UTI, a 3.5-fold higher IR of impotence, and a 7-fold higher IR of breast disorders, at 12 months compared with controls (Table 4). The IRs of UTI and impotence over time were stable among controls but declined among CaP patients. For instance, the IRs of UTI, among CaP patients, were 867 per 10,000 person-years [PY], which was almost 5-fold higher than controls, during the first 12 -month period, and 552 per 10,000 PY, which was 3.5-fold higher than controls, during the 48 -month period after diagnosis. The IRs of breast disorders changed little over time among both $\mathrm{CaP}$ patients and controls. CaP patients had $40 \%$ lower IR of stroke at 12 months and $30 \%$ to $40 \%$ higher IR of hypertension and congestive heart failure at 48 months only. There were no other outcomes that differed substantially between $\mathrm{CaP}$ patients and controls.

Men with elevated PSA but no CaP also had a higher IR of UTI (over 5-fold for the first 12-month period and 2.8fold for the 48-month period) and slightly higher IR of hypertension, compared with controls (Table 4). IRs of impotence and breast disorders were similar between cases and controls. Men with elevated PSA experienced a 40\% higher rate of type II diabetes and a $60 \%$ lower rate of lowerextremity arterial occlusive disease during the first 12-month period after the first elevated PSA test result. However, the differences were smaller and not statistically significant for the 48-month period. No other outcomes differed substantially between elevated PSA/no CaP cases and their controls. 
TABLE 2: Prevalence (and 95\% CI) of selected comorbidities of interest among CaP patients and men with elevated PSA but no CaP, compared with matched controls, during 12 months prior to the index date in the General Practice Research Database (GPRD, 1998-2008) ${ }^{1}$.

\begin{tabular}{|c|c|c|c|c|c|c|}
\hline \multirow{2}{*}{ Comorbidity } & \multicolumn{3}{|c|}{$\mathrm{CaP}$ patients and matched controls } & \multicolumn{3}{|c|}{ Men with elevated PSA but no CaP and matched controls } \\
\hline & $\begin{array}{c}\text { Cases } \\
(n=2,616)\end{array}$ & $\begin{array}{c}\text { Controls } \\
(n=2,616)\end{array}$ & OR $(95 \% \mathrm{CI})^{2}$ & $\begin{array}{c}\text { Cases } \\
(n=10,128)\end{array}$ & $\begin{array}{c}\text { Controls } \\
(n=10,128)\end{array}$ & OR $(95 \% \mathrm{CI})^{2}$ \\
\hline $\begin{array}{l}\text { Urinary tract } \\
\text { infection }\end{array}$ & $8.3(7.2,9.3)$ & $2.6(2.0,3.2)$ & $3.4(2.5,4.5)^{*}$ & $7.6(7.1,8.1)$ & $1.7(1.5,2.0)$ & $4.7(4.0,5.6)^{*}$ \\
\hline Impotence & $4.0(3.2,4.7)$ & $2.4(1.9,3.0)$ & $1.6(1.2,2.3)^{*}$ & $3.7(3.3,4.1)$ & $2.9(2.5,3.2)$ & $1.3(1.1,1.5)^{*}$ \\
\hline Breast disorders & $0.2(0.0,0.4)$ & $0.2(0.0,0.4)$ & $0.8(0.2,3.3)$ & $0.1(0.1,0.2)$ & $0.2(0.1,0.3)$ & $0.6(0.3,1.3)$ \\
\hline Hypertension & $7.5(6.5,8.5)$ & $6.7(5.7,7.6)$ & $1.1(0.9,1.4)$ & $5.6(5.1,6.0)$ & $5.2(4.8,5.6)$ & $1.1(0.95,1.2)$ \\
\hline Stroke & $1.7(1.2,2.2)$ & $1.6(1.2,2.1)$ & $1.0(0.6,1.6)$ & $1.0(0.8,1.2)$ & $0.9(0.8,1.1)$ & $1.1(0.8,1.4)$ \\
\hline $\begin{array}{l}\text { Acute coronary } \\
\text { syndrome }\end{array}$ & $0.9(0.6,1.3)$ & $1.0(0.6,1.4)$ & $0.9(0.5,1.7)$ & $0.6(0.5,0.8)$ & $0.8(0.7,1.0)$ & $0.7(0.5,1.02)$ \\
\hline Angina pectoris & $2.7(2.1,3.3)$ & $3.0(2.4,3.7)$ & $0.9(0.6,1.3)$ & $1.6(1.4,1.9)$ & $1.8(1.5,2.0)$ & $0.9(0.7,1.1)$ \\
\hline Arrythmia & $3.0(2.3,3.6)$ & $2.7(2.1,3.3)$ & $1.1(0.8,1.5)$ & $1.6(1.4,1.9)$ & $1.7(1.5,2.0)$ & $0.9(0.7,1.2)$ \\
\hline Myocardial infarction & $0.6(0.3,0.9)$ & $0.7(0.4,1.0)$ & $0.9(0.4,1.8)$ & $0.4(0.2,0.5)$ & $0.6(0.4,0.7)$ & $0.7(0.4,1.02)$ \\
\hline $\begin{array}{l}\text { Congestive heart } \\
\text { failure }\end{array}$ & $1.4(0.9,1.8)$ & $1.5(1.0,2.0)$ & $0.9(0.6,1.5)$ & $0.7(0.6,0.9)$ & $0.9(0.7,1.1)$ & $0.8(0.6,1.1)$ \\
\hline Hyperlipidemia & $2.4(1.8,3.0)$ & $2.4(1.8,3.0)$ & $1.0(0.7,1.5)$ & $2.0(1.8,2.3)$ & $2.4(2.1,2.7)$ & $0.8(0.7,1.02)$ \\
\hline $\begin{array}{l}\text { Low-extremity } \\
\text { arterial occlusive } \\
\text { disease }\end{array}$ & $0.6(0.3,0.9)$ & $0.5(0.2,0.8)$ & $1.1(0.5,2.6)$ & $0.4(0.3,0.5)$ & $0.5(0.3,0.6)$ & $0.8(0.5,1.3)$ \\
\hline Type II diabetes & $2.3(1.7,2.8)$ & $2.5(1.9,3.1)$ & $0.9(0.6,1.3)$ & $2.0(1.7,2.3)$ & $3.1(2.7,3.4)$ & $0.6(0.5,0.8)^{*}$ \\
\hline
\end{tabular}

${ }^{1}$ Index date was the date of initial CaP diagnosis for prostate cancer $(\mathrm{CaP})$ patients; the date of first elevated PSA test result for men with elevated PSA; the same index date as their matched cases for controls. $\mathrm{CI}=$ confidence interval.

${ }^{2}$ Odds ratio and $95 \%$ confidence interval.

* Significant difference between cases and their matched controls $(P<0.05)$.

TABle 3: Cumulative incidence (\%and 95\% CI) of specific comorbidities of interest across total follow-up after index date among CaP patients, men with elevated PSA but no CaP, and their matched controls in the General Practice Research Database (GPRD, 1998-2008) ${ }^{1}$.

\begin{tabular}{|c|c|c|c|c|c|c|}
\hline \multirow{2}{*}{ Comorbidity } & \multicolumn{3}{|c|}{ CaP patients and matched controls } & \multicolumn{3}{|c|}{ Men with elevated PSA but no CaP and matched controls } \\
\hline & $\begin{array}{c}\text { Cases } \\
(n=2,616)\end{array}$ & $\begin{array}{c}\text { Controls } \\
(n=2,616)\end{array}$ & OR $(95 \% \mathrm{CI})^{2}$ & $\begin{array}{c}\text { Cases } \\
(n=10,128)\end{array}$ & $\begin{array}{c}\text { Controls } \\
(n=10,128)\end{array}$ & OR $(95 \% \mathrm{CI})^{2}$ \\
\hline $\begin{array}{l}\text { Urinary tract } \\
\text { infection }\end{array}$ & $18.0(16.2,19.9)$ & $7.7(6.6,8.9)$ & $2.6(2.2,3.2)^{*}$ & $11.0(10.3,11.7)$ & $4.5(4.1,5.0)$ & $2.6(2.3,2.9)^{*}$ \\
\hline Impotence & $12.7(11.3,14.3)$ & $7.0(6.0,8.1)$ & $1.9(1.6,2.4)^{*}$ & $6.6(6.0,7.1)$ & $6.3(5.8,6.9)$ & $1.0(0.9,1.2)$ \\
\hline Breast disorders & $3.3(2.7,4.1)$ & $1.1(0.7,1.6)$ & $3.0(2.0,4.8)^{*}$ & $0.7(0.5,0.8)$ & $0.6(0.4,0.7)$ & $1.2(0.8,1.7)$ \\
\hline Hypertension & $15.2(13.3,17.1)$ & $14.6(12.8,16.5)$ & $1.0(0.9,1.3)$ & $12.6(11.8,13.5)$ & $11.8(11,12.7)$ & $1.1(0.97,1.2)$ \\
\hline Stroke & $4.7(3.9,5.7)$ & $7.1(6.0,8.2)$ & $0.7(0.5,0.8)^{*}$ & $2.9(2.5,3.2)$ & $3.4(3.0,3.8)$ & $0.8(0.7,0.99)^{*}$ \\
\hline $\begin{array}{l}\text { Acute coronary } \\
\text { syndrome }\end{array}$ & $3.6(2.8,4.4)$ & $3.8(3.0,4.7)$ & $0.9(0.7,1.3)$ & $2.1(1.8,2.4)$ & $2.3(2.0,2.7)$ & $0.9(0.7,1.07)$ \\
\hline Angina pectoris & $3.7(2.9,4.6)$ & $3.4(2.6,4.2)$ & $1.1(0.8,1.5)$ & $1.9(1.6,2.2)$ & $2.2(1.9,2.5)$ & $0.8(0.7,1.04)$ \\
\hline Arrhythmia & $6.5(5.5,7.7)$ & $7.8(6.7,9.0)$ & $0.8(0.7,1.04)$ & $4.5(4.1,5.0)$ & $4.8(4.4,5.3)$ & $0.9(0.8,1.1)$ \\
\hline Myocardial infarction & $2.9(2.3,3.7)$ & $3.1(2.4,3.9)$ & $0.9(0.7,1.3)$ & $1.7(1.4,1.9)$ & $1.9(1.6,2.2)$ & $0.9(0.7,1.1)$ \\
\hline $\begin{array}{l}\text { Congestive heart } \\
\text { failure }\end{array}$ & $5.6(4.7,6.6)$ & $5.2(4.4,6.2)$ & $1.1(0.8,1.4)$ & $1.8(1.6,2.1)$ & $2.3(2.0,2.6)$ & $0.8(0.6,0.9)^{*}$ \\
\hline Hyperlipidemia & $6.6(5.6,7.8)$ & $8.6(7.4,9.9)$ & $0.8(0.6,0.9)^{*}$ & $5.9(5.4,6.4)$ & $5.6(5.2,6.2)$ & $1.0(0.9,1.2)$ \\
\hline $\begin{array}{l}\text { Lower extremity } \\
\text { arterial occlusive } \\
\text { disease }\end{array}$ & $1.5(1.0,2.0)$ & $2.2(1.6,2.8)$ & $0.7(0.4,1.05)$ & $0.8(0.6,1.0)$ & $1.0(0.8,1.3)$ & $0.7(0.5,1.002)$ \\
\hline Diabetes type II & $5.6(4.7,6.7)$ & $6.4(5.4,7.5)$ & $0.9(0.7,1.1)$ & $3.9(3.5,4.4)$ & $4.4(3.9,4.8)$ & $0.9(0.8,1.04)$ \\
\hline
\end{tabular}

${ }^{1}$ Index date was the date of initial CaP diagnosis for prostate cancer (CaP) patients; the date of first elevated PSA test result for men with elevated PSA; the same index date as their matched cases for controls. $\mathrm{CI}$ = confidence interval; cumulative incidence is across total follow-up period.

${ }^{2}$ Odds ratio and $95 \%$ confidence interval.

* Significant difference between cases and their matched controls $(P<0.05)$. 
4.3. Prevalence of General Comorbidities. Across all four groups, cardiovascular-related issues were the most common comorbidity among men of this age (data not shown). CaP patients had higher prevalence of urinary tract signs and symptoms than matched controls; the prevalence was $43 \%$ during the 12-month period prior to $\mathrm{CaP}$ diagnosis then dropped to $19 \%$ during the 12 -month period after $\mathrm{CaP}$ diagnosis and was 7\% and $8 \%$ among controls in the 12 month period before and after the index date, respectively (Figure 1). Men with elevated PSA also had higher prevalence of urinary tract signs and symptoms (29\% and 31\% during the 12-month period before and after the elevated PSA results, resp.), compared with controls (6\% to $7 \%$ across both periods).

4.4. Prevalence of Concomitant Medication Use. Medication use was examined in the subgroup of men in GPRD from 2003 to 2008 . During both the 12 -month period before and the 12-month period after the index date, the most commonly used medications among men across the four cohorts included nonopioid analgesics and nonsteroidal anti-inflammatory drugs (NSAIDs, $40 \%$ to 50\%), statins and antiplatelet drugs ( $27 \%$ to $37 \%)$, opioid analgesics, angiotensin-converting enzyme inhibitors, beta-adrenoceptor blocking drugs, and calcium channel blockers ( $20 \%$ to $30 \%$, data not shown).

Table 5 highlighted the prevalence of concomitant medication use that was statistically significantly different between $\mathrm{CaP}$ patients and their controls or between men with elevated PSA but no CaP and their controls. Uses of alpha blockers in urinary retention, alpha adrenoceptor blocking drugs, sulphonamides and trimethoprim, and quinolones were 2- to 4fold more common for CaP patients before and after index date, compared to matched controls. For men with elevated PSA compared to controls, use of these same medications was 2- to 4-fold more common for cases than controls before index date and 3- to 5-fold more common after index date. After diagnosis, use of lidocaine/lignocaine in anaesthesia was 10-fold higher in $\mathrm{CaP}$ patients than controls, compared to only 2-fold higher prediagnosis. Prostate cancer drugs and gonadorelin analogues, drugs affecting gonadotrophins, male sex hormones, and antagonists were commonly used among CaP patients, especially after cancer diagnosis. More men with elevated PSA but no CaP were on alpha-blockers in urinary retention, alpha-adrenoceptor blocking drugs, male sex hormones and antagonists, and statins during the 12month period after (versus before) the index date.

4.5. All-Cause and Cause-Specific Mortality and Survival. $\mathrm{CaP}$ patients had the poorest survival, with a 2.6-fold higher all-cause mortality compared to their matched controls (Figure 2). Controls matched to $\mathrm{CaP}$ patients had slightly higher all-cause mortality than controls matched to men with elevated PSA, likely due to their older age. In contrast, all-cause mortality was slightly lower among men with elevated PSA compared to their matched controls. Of the 2,075 deaths in these four cohorts, we were able to link electronic medical data to death certificates for 1,226 (59\%) patients. Of these, the underlying causes of death were available for 1,194 men. Table 6 presents the underlying causes of

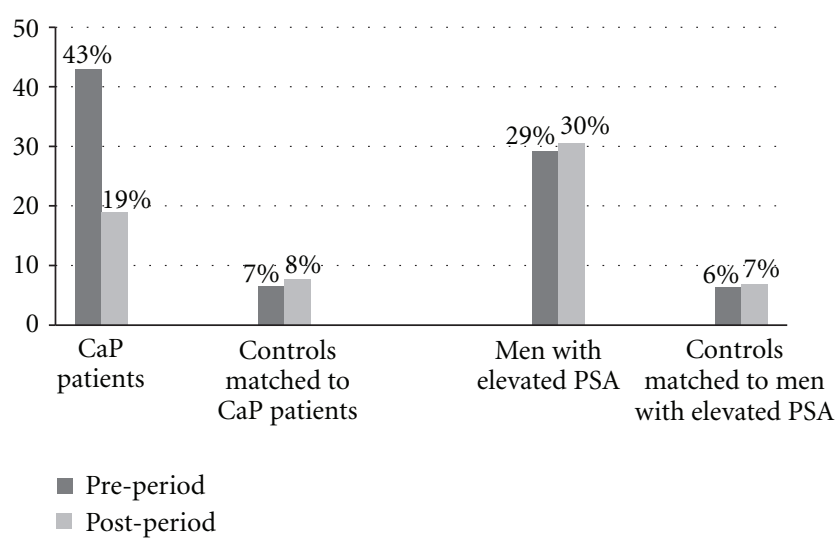

Figure 1: Prevalence of urinary tract signs and symptoms among $\mathrm{CaP}$ patients, men with elevated PSA but no $\mathrm{CaP}$, and matched controls during 12 months prior to and 12 months after the index date in the General Practice Research Database (GPRD, 1998-2008) (Index date was the date of initial CaP diagnosis for prostate cancer (CaP) patients; the date of first elevated PSA test result for men with elevated PSA but no CaP; the same index date as their matched cases for controls). The prevalence odds ratios, OR ( $95 \%$ confidence interval, CI), were 11.3 (9.5-13.6) during 12 months prior to the index date and 2.9 (2.5-3.5) during 12-months post the index date for $\mathrm{CaP}$ patients, compared to controls, and were 6.2 (5.6-6.8) during 12 months prior to the index date and 6.1 (5.6-6.7) during 12 months after the index date for men with elevated PSA but no $\mathrm{CaP}$, compared to controls. Among CaP patients, the prevalence OR (95\% CI) was $3.2(2.8-3.6) 12$ months prior to versus 12 months after the index date.

death among men who died within each group. Frequencies of more than $2 \%$ for individual event types and of more than $3 \%$ for systems of diseases were reported. Among CaP patients, nearly $60 \%(n=220)$ of the deaths were ascribed to neoplasms, and $58 \%(n=213)$ to CaP. In contrast, 12 men with elevated PSA died of $\mathrm{CaP}$ (i.e., $4.6 \%$ of 197 deaths), and no men died of $\mathrm{CaP}$ among controls. Next to neoplasms as an underlying cause, $25 \%$ of the deaths among $\mathrm{CaP}$ patients were ascribed to diseases of the circulatory system compared to men with elevated PSA and no CaP (46\%) and men in the two control groups ( $52 \%$ and $49 \%$ ). The percentage of deaths due to other underlying causes, such as respiratory and nervous systems, was lower among $\mathrm{CaP}$ patients compared to the other three groups of men. Among men with elevated PSA with no CaP and men in the two control groups, $46 \%$ to $51 \%$ of the deaths were due to diseases of circulatory system, as mentioned above, $17 \%$ to $21 \%$ due to diseases of respiratory systems, and $8 \%$ to $13 \%$ due to neoplasms.

\section{Discussion}

This study examined the prevalence and incidence of comorbidities and the prevalence of concomitant medication use among men with $\mathrm{CaP}$, men deemed at increased risk of $\mathrm{CaP}$ due to elevated PSA, and control groups that were matched to these men on age, practice, and duration and calendar period of follow-up in the GPRD. 
TABLE 4: Incidence rates (IR, per 10,000 person-years; 95\% CI) for selected comorbidities among CaP patients and men with elevated PSA but no CaP, compared with matched controls, during 12 and 48 months after the index date in the General Practice Research Database $($ GPRD, 1998-2008)1.

\begin{tabular}{|c|c|c|c|c|c|c|}
\hline \multirow{2}{*}{ Comorbidity } & \multicolumn{3}{|c|}{$\mathrm{CaP}$ patients and matched controls } & \multicolumn{3}{|c|}{ Men with elevated PSA but no CaP and matched controls } \\
\hline & $\begin{array}{c}\text { Cases } \\
(n=2,616)\end{array}$ & $\begin{array}{c}\text { Controls } \\
(n=2,616)\end{array}$ & $\mathrm{RR}(95 \% \mathrm{CI})^{2}$ & $\begin{array}{c}\text { Cases } \\
(n=10,128)\end{array}$ & $\begin{array}{c}\text { Controls } \\
(n=10,128)\end{array}$ & $\mathrm{RR}(95 \% \mathrm{CI})^{2}$ \\
\hline \multicolumn{7}{|c|}{ Urinary tract infection } \\
\hline$<12 \mathrm{mo}$ & $867(740,1009)$ & $179(128,243)$ & $4.9(3.4,6.8)^{*}$ & $569(517,625)$ & $104(84,128)$ & $5.4(4.3,6.8)^{*}$ \\
\hline$<48 \mathrm{mo}$ & $552(492,616)$ & $156(129,188)$ & $3.5(2.8,4.4)^{*}$ & $367(344,395)$ & $130(116,145)$ & $2.8(2.5,3.2)^{*}$ \\
\hline \multicolumn{7}{|c|}{ Impotence } \\
\hline$<12 \mathrm{mo}$ & $642(539,759)$ & $181(130,246)$ & $3.5(2.5,5.0)^{*}$ & $256(223,292)$ & $237(205,272)$ & $1.1(0.9,1.3)$ \\
\hline$<48 \mathrm{mo}$ & $442(392,498)$ & $174(145,207)$ & $2.5(2.1,3.1)^{*}$ & $215(197,235)$ & $197(180,215)$ & $1.1(0.96,1.2)$ \\
\hline \multicolumn{7}{|c|}{ Breast disorders } \\
\hline$<12$ mo & $90(56,136)$ & $12(3,35)$ & $7.4(2.2,24.8)^{*}$ & $18(10,28)$ & $14(7,23)$ & $1.3(0.6,2.7)$ \\
\hline$<48 \mathrm{mo}$ & $93(72,118)$ & $23(14,36)$ & $4.0(2.4,6.6)^{*}$ & $18(13,23)$ & $16(11,21)$ & $1.1(0.7,1.7)$ \\
\hline \multicolumn{7}{|c|}{ Hypertension } \\
\hline$<12 \mathrm{mo}$ & $508(403,634)$ & $401(309,511)$ & $1.3(0.9,1.8)$ & $499(444,558)$ & $355(310,405)$ & $1.4(1.2,1.7)^{*}$ \\
\hline$<48 \mathrm{mo}$ & $455(395,522)$ & $354(305,410)$ & $1.3(1.05,1.6)^{*}$ & $409(380,441)$ & $359(332,388)$ & $1.1(1.02,1.3)^{*}$ \\
\hline \multicolumn{7}{|c|}{ Stroke } \\
\hline$<12 \mathrm{mo}$ & $110(71,162)$ & $185(13,251)$ & $0.6(0.4,0.97)^{*}$ & $78(61,98)$ & $93(75,116)$ & $0.8(0.6,1.1)$ \\
\hline$<48 \mathrm{mo}$ & $127(102,156)$ & $157(129,188)$ & $0.8(0.6,1.1)$ & $83(72,95)$ & $97(86,110)$ & $0.9(0.7,1.0)$ \\
\hline \multicolumn{7}{|c|}{ Acute coronary syndrome } \\
\hline$<12 \mathrm{mo}$ & $129(86,185)$ & $76(44,121)$ & $1.7(0.9,3.1)$ & $52(39,70)$ & $56(41,73)$ & $0.9(0.6,1.4)$ \\
\hline$<48 \mathrm{mo}$ & $96(75,123)$ & $78(60,101)$ & $1.2(0.9,1.7)$ & $62(53,72)$ & $60(51,71)$ & $1.0(0.8,1.3)$ \\
\hline \multicolumn{7}{|c|}{ Angina pectoris } \\
\hline$<12$ mo & $113(72,168)$ & $81(47,129)$ & $1.4(0.7,2.6)$ & $68(51,87)$ & $76(58,97)$ & $0.9(0.6,1.3)$ \\
\hline$<48 \mathrm{mo}$ & $104(81,133)$ & $80(60,104)$ & $1.3(0.9,1.9)$ & $60(51,71)$ & $66(56,77)$ & $0.9(0.7,1.1)$ \\
\hline \multicolumn{7}{|c|}{ Arrhythmia } \\
\hline$<12$ mo & $156(108,218)$ & $134(91,192)$ & $1.2(0.7,1.9)$ & $134(111,161)$ & $131(108,157)$ & $1.0(0.8,1.3)$ \\
\hline$<48 \mathrm{mo}$ & $164(134,198)$ & $139(113,169)$ & $1.2(0.9,1.5)$ & $134(120,149)$ & $140(125,155)$ & $1.0(0.8,1.1)$ \\
\hline \multicolumn{7}{|c|}{ Myocardial infarction } \\
\hline$<12 \mathrm{mo}$ & $96(60,145)$ & $61(34,103)$ & $1.6(0.8,3.1)$ & $35(24,50)$ & $50(37,67)$ & $0.7(0.4,1.1)$ \\
\hline$<48 \mathrm{mo}$ & $77(58,101)$ & $61(45,82)$ & $1.3(0.8,1.9)$ & $50(42,59)$ & $50(42,59)$ & $1.0(0.8,1.3)$ \\
\hline \multicolumn{7}{|c|}{ Congestive heart failure } \\
\hline$<12 \mathrm{mo}$ & $144(100,201)$ & $85(52,131)$ & $1.7(0.98,3.0)$ & $49(36,65)$ & $58(43,75)$ & $0.8(0.6,1.3)$ \\
\hline$<48 \mathrm{mo}$ & $145(118,176)$ & $106(84,132)$ & $1.4(1.02,1.8)^{*}$ & $52(44,62)$ & $65(56,75)$ & $0.8(0.6,1.003)$ \\
\hline \multicolumn{7}{|c|}{ Hyperlipidemia } \\
\hline$<12 \mathrm{mo}$ & $140(95,199)$ & $196(142,264)$ & $0.7(0.4,1.1)$ & $234(202,269)$ & $194(165,226)$ & $1.2(0.98,1.5)$ \\
\hline$<48 \mathrm{mo}$ & $156(128,189)$ & $187(156,221)$ & $0.8(0.6,1.1)$ & $189(172,207)$ & $172(156,190)$ & $1.1(0.96,1.3)$ \\
\hline \multicolumn{7}{|c|}{ Lower-extremity arterial occlusive disease } \\
\hline$<12 \mathrm{mo}$ & $50(26,87)$ & $33(14,65)$ & $1.5(0.6,3.6)$ & $19(11,30)$ & $44(31,59)$ & $0.4(0.2,0.8)^{*}$ \\
\hline$<48 \mathrm{mo}$ & $34(22,50)$ & $46(32,63)$ & $0.7(0.4,1.2)$ & $23(18,29)$ & $29(23,37)$ & $0.8(0.6,1.1)$ \\
\hline \multicolumn{7}{|c|}{ Diabetes, Type II } \\
\hline$<12 \mathrm{mo}$ & $131(89,188)$ & $97(61,147)$ & $1.4(0.8,2.3)$ & $181(154,211)$ & $126(103,152)$ & $1.4(1.1,1.8)^{*}$ \\
\hline$<48 \mathrm{mo}$ & $154(126,187)$ & $144(118,174)$ & $1.1(0.8,1.4)$ & $122(109,136)$ & $126(112,141)$ & $1.0(0.8,1.1)$ \\
\hline
\end{tabular}

${ }^{1}$ Index date was the date of initial CaP diagnosis for prostate cancer $(\mathrm{CaP})$ patients; the date of first elevated PSA test result for men with elevated PSA; the same index date as their matched cases for controls. $\mathrm{CI}=$ confidence interval.

${ }^{2}$ Rate ratio (95\% confidence interval) comparing cases and their controls.

* Significant difference between cases and their matched controls $(P<0.05)$. 
TABLE 5: Prevalence (and 95\% CI) of concomitant medication use that was statistically significantly different between CaP patients and their controls or between men with elevated PSA but no CaP and their controls in the General Practice Research Database (GPRD, 2003-2008) ${ }^{1}$.

\begin{tabular}{|c|c|c|c|}
\hline & Cases & Controls & OR $(95 \% \mathrm{CI})$ \\
\hline \multicolumn{4}{|c|}{ CaP patients $(n=1,345)$ and matched controls $(n=1,345)$ : during 12 months prior to the index date } \\
\hline Alpha blockers (in urinary retention) & $24.3(22.0,26.6)$ & $7.1(5.7,8.4)$ & $4.2(3.3,5.4)$ \\
\hline Alpha adrenoceptor blocking drugs & $20.7(18.6,22.9)$ & $6.7(5.4,8.0)$ & $3.6(2.8,4.7)$ \\
\hline Sulphonamides and trimethoprim & $12.2(10.4,13.9)$ & $3.9(2.9,5.0)$ & $3.4(2.4,4.8)$ \\
\hline Quinolones & $8.8(7.3,10.3)$ & $3.1(2.2,4.1)$ & $3.0(2.1,4.4)$ \\
\hline Lidocaine/lignocaine (in anaesthesia) & $6.4(5.1,7.7)$ & $3.0(2.1,3.9)$ & $2.2(1.5,3.4)$ \\
\hline Cephalosporins and other beta lactams & $6.9(5.6,8.3)$ & $4.2(3.1,5.2)$ & $1.7(1.2,2.4)$ \\
\hline Osmotic laxatives & $10.6(8.9,12.2)$ & $7.4(6.0,8.8)$ & $1.5(1.1,2.0)$ \\
\hline Thiazides and related diuretics & $20.3(18.1,22.4)$ & $17.0(14.9,19.0)$ & $1.2(1.02,1.5)$ \\
\hline Antiplatelet drugs & $29.7(27.2,32.1)$ & $34.3(31.8,36.9)$ & $0.8(0.7,0.95)$ \\
\hline Statins & $28.8(26.4,31.3)$ & $32.8(30.3,35.3)$ & $0.8(0.7,0.98)$ \\
\hline Prostate cancer and gonadorelin analogues & $7.9(6.4,9.3)$ & $-^{2}$ & \\
\hline Emollient skin preparations & $7.9(6.4,9.3)$ & $-^{2}$ & \\
\hline Male sex hormones and antagonists & $6.2(5.0,7.5)$ & $-^{2}$ & \\
\hline \multicolumn{4}{|c|}{ CaP patients $(n=1,345)$ and matched controls $(n=1,345)$ : during 12 months after the index date } \\
\hline Lidocaine/lignocaine (in anaesthesia) & $17.8(15.8,19.9)$ & $2.0(1.3,2.8)$ & $10.6(7.0,16.5)$ \\
\hline Alpha blockers (in urinary retention) & $26.8(24.5,29.2)$ & $8.0(6.5,9.4)$ & $4.2(3.4,5.4)$ \\
\hline Alpha adrenoceptor blocking drugs & $22.8(20.6,25.1)$ & $7.4(6.0,8.8)$ & $3.7(2.9,4.8)$ \\
\hline Quinolones & $8.4(6.9,9.9)$ & $3.3(2.4,4.3)$ & $2.6(1.8,3.9)$ \\
\hline Drugs for urinary frequency, enuresis and incontinence & $10.6(8.9,12.2)$ & $4.7(3.6,5.8)$ & $2.4(1.8,3.3)$ \\
\hline Prophylaxis of migraine & $6.5(5.2,7.8)$ & $3.0(2.1,4.0)$ & $2.2(1.5,3.3)$ \\
\hline Motility stimulants & $3.9(2.8,4.9)$ & $1.8(1.1,2.5)$ & $2.2(1.3,3.8)$ \\
\hline Drugs for erectile dysfunction & $12.3(10.6,14.1)$ & $5.9(4.6,7.1)$ & $2.3(1.7,3.0)$ \\
\hline Osmotic laxatives & $15.0(13.1,16.9)$ & $7.6(6.2,9.0)$ & $2.2(1.7,2.8)$ \\
\hline Sulphonamides and trimethoprim & $10.7(9.1,12.4)$ & $4.6(3.5,5.7)$ & $1.9(1.4,2.6)$ \\
\hline Vasodilator antihypertensive drugs & $7.4(6.0,8.8)$ & $3.9(2.8,4.9)$ & $2.0(1.4,2.9)$ \\
\hline $\begin{array}{l}\text { Compound haemorrhoidal preparations with } \\
\text { corticosteroids }\end{array}$ & $4.2(3.2,5.3)$ & $2.2(1.4,3.0)$ & $1.9(1.2,3.1)$ \\
\hline Stimulant laxatives & $8.8(7.3,10.3)$ & $4.8(3.7,6.0)$ & $1.9(1.4,2.6)$ \\
\hline Anxiolytics and neuroleptics (in anaesthesia) & $6.0(4.8,7.3)$ & $3.3(2.4,4.3)$ & $1.9(1.3,2.8)$ \\
\hline Tricyclic and related antidepressant drugs & $7.1(5.7,8.4)$ & $4.0(3.0,5.1)$ & $1.8(1.3,2.6)$ \\
\hline Oral iron & $6.6(5.3,7.9)$ & $4.0(3.0,5.1)$ & $1.7(1.2,2.4)$ \\
\hline Neuropathic pain & $6.5(5.2,7.9)$ & $4.0(3.0,5.1)$ & $1.7(1.2,2.4)$ \\
\hline Drugs used in nausea and vertigo & $9.4(7.8,10.9)$ & $5.9(4.6,7.1)$ & $1.7(1.2,2.2)$ \\
\hline Antimotility drugs & $6.5(5.2,7.9)$ & $4.2(3.1,5.2)$ & $1.6(1.1,2.3)$ \\
\hline Hypnotics & $9.4(7.8,10.9)$ & $6.8(5.4,8.1)$ & $1.4(1.1,1.9)$ \\
\hline Acute attacks of gout & $13.9(12.1,15.8)$ & $10.3(8.7,12.0)$ & $1.4(1.1,1.8)$ \\
\hline Urinary-tract infections & $20.1(18.0,22.3)$ & $15.2(13.3,17.2)$ & $1.4(1.1,1.7)$ \\
\hline Broad-spectrum penicillins & $22.2(20.0,24.5)$ & $18.2(16.2,20.3)$ & $1.3(1.1,1.6)$ \\
\hline Topical corticosteroids & $21.5(19.3,23.7)$ & $17.6(15.6,19.7)$ & $1.3(1.1,1.6)$ \\
\hline Statins & $32.2(29.7,34.7)$ & $37.2(34.7,39.8)$ & $0.8(0.7,0.9)$ \\
\hline Antiplatelet drugs & $32.1(29.6,34.6)$ & $37.4(34.8,40.0)$ & $0.8(0.7,0.9)$ \\
\hline Prostate cancer and gonadorelin analogues & $71.8(69.4,74.2)$ & $-^{2}$ & \\
\hline Drugs affecting gonadotrophins & $34.1(31.5,36.6)$ & $-^{2}$ & \\
\hline Breast cancer & $23.9(21.6,26.1)$ & $-^{2}$ & \\
\hline Male sex hormones and antagonists & $16.8(14.8,18.8)$ & $-^{2}$ & \\
\hline
\end{tabular}


TABLE 5: Continued.

\begin{tabular}{|c|c|c|c|}
\hline & Cases & Controls & OR $(95 \% \mathrm{CI})$ \\
\hline Ventricular arrhythmias & $11.8(10.1,13.5)$ & $-^{2}$ & \\
\hline Leg bags & $6.9(5.6,8.3)$ & $-^{2}$ & \\
\hline Night drainage bags & $5.1(3.9,6.2)$ & $-^{2}$ & \\
\hline \multicolumn{4}{|c|}{ Men with elevated PSA but no CaP $(n=7,725)$ and matched controls $(n=7,725)$ : during 12 months prior to the index date } \\
\hline Sulphonamides and trimethoprim & $10.6(9.9,11.3)$ & $3.0(2.6,3.4)$ & $3.9(3.3,4.5)$ \\
\hline Alpha blockers (in urinary retention) & $16.8(15.9,17.6)$ & $7.4(6.8,7.9)$ & $2.5(2.3,2.8)$ \\
\hline Alpha adrenoceptor blocking drugs & $14.3(13.5,15.1)$ & $6.8(6.2,7.4)$ & $2.3(2.0,2.6)$ \\
\hline Quinolones & $5.6(5.1,6.1)$ & $2.8(2.4,3.2)$ & $2.1(1.8,2.5)$ \\
\hline Male sex hormones and antagonists & $3.2(2.8,3.6)$ & $1.6(1.3,1.8)$ & $2.1(1.6,2.6)$ \\
\hline Cephalosporins and other beta lactams & $7.2(6.6,7.7)$ & $3.6(3.2,4.1)$ & $2.0(1.8,2.4)$ \\
\hline Biguanides & $4.4(3.9,4.8)$ & $6.6(6.0,7.1)$ & $0.7(0.6,0.8)$ \\
\hline Sulphonylureas & $3.2(2.8,3.6)$ & $4.7(4.2,5.2)$ & $0.7(0.6,0.8)$ \\
\hline Diagnostic and monitoring agents for diabetes mellitus & $1.7(1.4,2.0)$ & $2.3(2.0,2.6)$ & $0.7(0.6,0.9)$ \\
\hline Other antianginal drugs & $1.3(1.1,1.6)$ & $1.8(1.5,2.1)$ & $0.7(0.6,0.9)$ \\
\hline Nitrates & $7.7(7.1,8.3)$ & $9.4(8.7,10)$ & $0.8(0.7,0.9)$ \\
\hline Loop diuretics & $5.9(5.4,6.5)$ & $7.4(6.8,8.0)$ & $0.8(0.7,0.9)$ \\
\hline Nonopioid analgesics & $39.1(38.0,40.2)$ & $43.8(42.7,44.9)$ & $0.8(0.8,0.9)$ \\
\hline Control of epilepsy & $4.2(3.8,4.7)$ & $5.1(4.6,5.6)$ & $0.8(0.7,0.96)$ \\
\hline Neuropathic pain & $3.9(3.5,4.3)$ & $4.6(4.2,5.1)$ & $0.8(0.7,0.98)$ \\
\hline Antimotility drugs & $2.8(2.4,3.1)$ & $3.3(2.9,3.7)$ & $0.8(0.7,0.995)$ \\
\hline Statins & $28.4(26.6,30.3)$ & $32.5(30.7,34.4)$ & $0.8(0.8,0.9)$ \\
\hline Antiplatelet drugs & $26.5(24.6,28.4)$ & $30.5(28.7,32.4)$ & $0.8(0.8,0.9)$ \\
\hline Opioid analgesics & $19.6(18.7,20.5)$ & $21.8(20.8,22.7)$ & $0.9(0.8,0.9)$ \\
\hline Beta adrenoceptor blocking drugs & $18.3(17.5,19.2)$ & $19.9(19.0,20.7)$ & $0.9(0.8,0.98)$ \\
\hline
\end{tabular}
Men with elevated PSA but no CaP $(n=7,725)$ and matched controls $(n=7,725)$ : during 12 months after the index date

\begin{tabular}{|c|c|c|c|}
\hline Male sex hormones and antagonists & $10.6(10.0,11.3)$ & $1.7(2.0,1.4)$ & $6.9(5.7,8.4)$ \\
\hline Alpha blockers (in urinary retention) & $32.2(31.1,33.2)$ & $8.0(8.6,7.4)$ & $5.5(5.0,6.0)$ \\
\hline Alpha adrenoceptor blocking drugs & $27.4(26.4,28.4)$ & $7.3(7.9,6.7)$ & $4.8(4.3,5.3)$ \\
\hline Sulphonamides and trimethoprim & $10.2(9.5,10.9)$ & $2.8(3.2,2.4)$ & $4.0(3.4,4.7)$ \\
\hline Quinolones & $9.3(8.7,10.0)$ & $3.1(3.4,2.7)$ & $3.3(2.8,3.8)$ \\
\hline Cephalosporins and other beta lactams & $7.4(6.8,8.0)$ & $3.9(4.3,3.4)$ & $2.0(1.7,2.3)$ \\
\hline Lidocaine/lignocaine (in anaesthesia) & $3.5(3.1,3.9)$ & $2.4(2.7,2.0)$ & $1.5(1.2,1.8)$ \\
\hline $\begin{array}{l}\text { Compound haemorrhoidal preparations with } \\
\text { corticosteroids }\end{array}$ & $2.9(2.5,3.3)$ & $2.3(2.6,1.9)$ & $1.3(1.1,1.6)$ \\
\hline Drugs for urinary frequency, enuresis and incontinence & $6.3(5.7,6.8)$ & $5.2(5.6,4.7)$ & $1.2(1.1,1.4)$ \\
\hline Drugs for erectile dysfunction & $7.4(6.8,8.0)$ & $6.3(6.9,5.8)$ & $1.2(1.08,1.4)$ \\
\hline Vasodilator antihypertensive drugs & $4.9(4.4,5.4)$ & $4.2(4.7,3.8)$ & $1.2(1.003,1.4)$ \\
\hline Biguanides & $4.9(4.4,5.4)$ & $7.2(7.8,6.7)$ & $0.7(0.6,0.8)$ \\
\hline Sulphonylureas & $3.4(3.0,3.8)$ & $4.7(5.2,4.2)$ & $0.7(0.6,0.8)$ \\
\hline Emollient bath additives & $1.7(1.4,2.0)$ & $2.3(2.6,2.0)$ & $0.7(0.6,0.9)$ \\
\hline Calcium supplements & $2.2(1.8,2.5)$ & $2.7(3.1,2.3)$ & $0.8(0.6,0.98)$ \\
\hline Vitamin D & $1.9(1.6,2.2)$ & $2.4(2.8,2.1)$ & $0.8(0.6,0.98)$ \\
\hline Nitrates & $7.5(6.9,8.1)$ & $9.4(10,8.7)$ & $0.8(0.7,0.9)$ \\
\hline Neuropathic pain & $4.3(3.9,4.8)$ & $5.1(5.6,4.6)$ & $0.8(0.7,0.98)$ \\
\hline Antiplatelet drugs & $29.4(28.4,30.4)$ & $32.9(34.0,31.9)$ & $0.8(0.8,0.9)$ \\
\hline Nonopioid analgesics & $42.6(41.5,43.7)$ & $45.9(47.0,44.7)$ & $0.9(0.8,0.9)$ \\
\hline
\end{tabular}


TABle 5: Continued.

\begin{tabular}{lccc}
\hline & Cases & Controls & OR $(95 \%$ CI $)$ \\
\hline Beta adrenoceptor blocking drugs & $18.5(17.6,19.4)$ & $20.6(21.5,19.7)$ & $0.9(0.8,0.9)$ \\
Loop diuretics & $7.0(6.4,7.6)$ & $8.1(8.7,7.5)$ & $0.9(0.8,0.96)$ \\
Emollient skin preparations & $7.4(6.8,8.0)$ & $8.5(9.1,7.9)$ & $0.9(0.8,0.97)$ \\
Nonsteroidal anti-inflammatory drugs & $42.8(41.7,43.9)$ & $44.7(45.8,43.6)$ & $0.9(0.9,0.98)$ \\
\hline
\end{tabular}

${ }^{1}$ Medications, listed by class per British National Formulary (BNF) header within the product files, were assessed among a subgroup of men in GPRD within the latter five years (i.e., index dates between August 1, 2003 and July 31, 2008), in order to provide a more up-to-date pattern for medication use. OR = odds ratio, $\mathrm{CI}=$ confidence interval. This table, ranked by magnitude of the $\mathrm{OR}$, includes only medications with significant ORs. For medications used by less than $2 \%$ in cases (or controls), only those used by $>5 \%$ by their matched patients were included. Index date was the date of initial CaP diagnosis for prostate cancer $(\mathrm{CaP})$ patients; the date of first elevated PSA test result for men with elevated PSA but no CaP; the same index date as their matched cases for controls.

${ }^{2}$ Blanks indicate that the frequency of medication use was $<2 \%$.

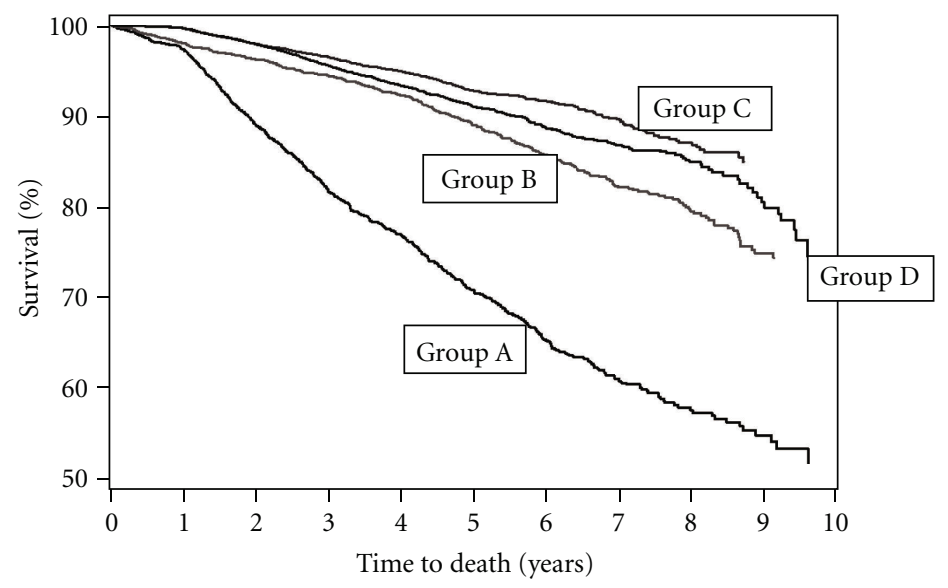

\begin{tabular}{|l|c|c|c|}
\hline Groups & $N$ & Death & $\begin{array}{c}\text { Mortality rate }(95 \% \text { CI), } \\
\text { per 10,000 person-year }\end{array}$ \\
\hline CaP patients (group A) & 2,616 & 682 & $661(613,713)$ \\
Controls for CaP (group B) & 2,616 & 311 & $256(228,286)$ \\
Men with elevated PSA but no CaP (group C) & 10,128 & 476 & $136(124,148)$ \\
Controls for men with elevated PSA but no CaP (group D) & 10,128 & 606 & $171(158,185)$ \\
\hline
\end{tabular}

Figure 2: Kaplan-Meier survival curve for CaP patients, men with elevated PSA but no CaP and matched controls in the General Practice Research Database (GPRD, 1998-2008). The rate ratio, RR (95\% confidence interval, CI), was 2.6 (2.3-3.0) for CaP patients and 0.8 (0.7-0.9) for men with elevated PSA but no CaP, compared to matched controls.

We included men with elevated PSA identified between August 1, 1998 and July 31, 2008 and found that a fairly high proportion $(\sim 20 \%)$ of these men had PSA levels over $10 \mathrm{ng} / \mathrm{mL}$ but had never been diagnosed with CaP. Although this observation seems inconsistent with the high specificity of the PSA test at the level of $>10 \mathrm{ng} / \mathrm{mL}$ [13], it may reflect the reality in UK. According to the UK Prostate Cancer Risk Management Programme [14], CaP screening was not offered for asymptomatic men during this time period, given that the extent of benefit and harm of such screening are still under debate [18-20]. Men with elevated PSA may or may not be further evaluated for CaP, due to the lack of agreement among primary care physicians regarding what PSA cutoffs should trigger patient referrals $[21,22]$.

Compared with controls, $\mathrm{CaP}$ patients had significantly higher incidence of UTI (2- to 5-fold), impotence (2- to 3 -fold), and breast disorders (3- to 7-fold) after diagnosis, which is consistent with earlier studies [23, 24]. Men with elevated PSA also had higher incidence (3- to 5-fold) of UTI, compared with controls. For several conditions, including UTI and impotence among CaP patients and UTI, hypertension, and diabetes among men with elevated PSA but no CaP, the incidence was the highest, and the differences between cases and controls were the greatest during the first 12 months of follow-up; rates were lower and differences were smaller at 48 months of follow-up. A plausible explanation may be that previously undiagnosed conditions are coming to medical attention after $\mathrm{CaP}$ diagnoses or the elevated PSA findings due to more intense medical scrutiny.

The prevalence and incidence of hypertension and cardiovascular-related comorbidities, including acute coronary syndrome, angina pectoris, arrhythmia, myocardial infarction, congestive heart failure, and lower extremity arterial 
TABLE 6: Underlying causes of deaths: CaP patients, men with elevated PSA but no CaP, and matched controls in the General Practice Research Database (GPRD, 1998-2008) ${ }^{1}$.

\begin{tabular}{|c|c|c|c|c|}
\hline & \multicolumn{2}{|c|}{$\mathrm{CaP}$ patients and matched controls } & \multicolumn{2}{|c|}{$\begin{array}{l}\text { Men with elevated PSA but no CaP and } \\
\text { matched controls }\end{array}$} \\
\hline & Cases (369 deaths) & Controls (263 deaths) & Cases (197 deaths) & Controls (365 deaths) \\
\hline Neoplasms (\% among all deaths) & 59.6 & 8.1 & 13.3 & 8.8 \\
\hline Prostate cancer & 57.7 & 0.0 & 4.6 & 0.0 \\
\hline Diseases of the circulatory system (\%) & 24.9 & 51.8 & 46.4 & 49.3 \\
\hline Acute myocardial infarction & 5.7 & 11.7 & 8.7 & 12.3 \\
\hline Chronic ischaemic heart disease & 4.6 & 11.2 & 10.6 & 10.1 \\
\hline Atherosclerotic heart disease & 2.7 & 6.1 & 3.4 & 8.2 \\
\hline $\begin{array}{l}\text { Stroke, not specified as } \\
\text { haemorrhage or infarction }\end{array}$ & 3.0 & 5.1 & 4.2 & 4.9 \\
\hline Cerebral infarction & 0.8 & 2.5 & 1.5 & 0.8 \\
\hline Cerebrovascular disease & 1.4 & 2.0 & 1.1 & 1.4 \\
\hline $\begin{array}{l}\text { Abdominal aortic aneurysm, } \\
\text { ruptured }\end{array}$ & 0.3 & 2.0 & 1.9 & 1.4 \\
\hline Diseases of the respiratory system (\%) & 6.8 & 17.3 & 19.0 & 21.4 \\
\hline Bronchopneumonia & 2.2 & 6.1 & 3.8 & 4.1 \\
\hline Pneumonia & 0.3 & 3.6 & 4.2 & 3.0 \\
\hline $\begin{array}{l}\text { Chronic obstructive pulmonary } \\
\text { disease }\end{array}$ & 2.2 & 2.5 & 7.2 & 6.8 \\
\hline Diseases of the nervous system (\%) & 1.4 & 6.6 & 4.2 & 3.8 \\
\hline Parkinson's disease & 1.1 & 2.0 & 1.5 & 1.4 \\
\hline Alzheimer's disease & 0.3 & 2.5 & 1.5 & 0.5 \\
\hline Diseases of the digestive system (\%) & 3.5 & 4.1 & 3.4 & 4.4 \\
\hline $\begin{array}{l}\text { Diseases of the genitourinary system } \\
(\%)\end{array}$ & 0.5 & 1.0 & 3.8 & 1.4 \\
\hline $\begin{array}{l}\text { External causes of morbidity and } \\
\text { mortality }^{2}(\%)\end{array}$ & 0.8 & 2.5 & 3.0 & 2.2 \\
\hline Others ${ }^{3}(\%)$ & 2.4 & 8.6 & 6.8 & 8.8 \\
\hline
\end{tabular}

${ }^{1}$ The linkage to the death certificate data was available for 1,226 patients, that is, 59\% of 2,075 deaths. Of these, 1,194 men had underlying cause of death record. The underlying causes of death were recorded and described according to the International Statistical Classification of Diseases and Related Health Problems 10th Revision (ICD-10) [17]. Frequencies of more than $2 \%$ for individual events and of more than $3 \%$ for systems of diseases were reported.

${ }^{2}$ Including accidents, intentional self-harm, event of undetermined intent, and complications of medical and surgical care.

${ }^{3}$ Other reasons include endocrine, nutritional and metabolic diseases, certain infectious and parasitic diseases, mental and behavioural disorders, diseases of the musculoskeletal system and connective tissue, symptoms, signs and abnormal clinical and laboratory findings, not elsewhere classified, and congenital malformations, deformations, and chromosomal abnormalities.

occlusive disease, were generally similar between CaP patients, men with elevated PSA, and controls. The prevalence of hypertension prior to the index date $(5-6 \%)$ was lower than in most population-based studies among older men or CaP patients [25-29]. However, comparing our results to the existing body of literature is particularly difficult, given the differences in study populations, study design, and outcome definitions. Moreover, many studies presented the prevalence data over multiple years, whereas in this study, we examined the prevalence during a 12-month period prior to $\mathrm{CaP}$ diagnosis or first elevated PSA result, and incidence after the index date.

When we examined the most frequently occurring comorbidities, the prevalence of urinary tract signs and symptoms remained similar over time for men with elevated PSA $(\sim 30 \%)$, despite an increase in alpha blocker use from $17 \%$ during the 12 months prior to the elevated PSA results to $32 \%$ during the 12 months after the elevated PSA results. For men with $\mathrm{CaP}$, the prevalence of urinary tract signs and symptoms was high (43\%) during the prediagnostic period and dropped to $19 \%$ after diagnosis, likely attributable to cancer treatment. Consistent with the study design that controls must not have CaP, elevated PSA, and/or any benign prostatic diseases, the prevalence of urinary tract signs and symptoms and alphablocker use were low at 6$8 \%$ over time among controls. Several medications, including NSAIDs, nonopioid analgesics, antiplatelet drugs, statins, ACE inhibitors, and/or calcium channel blockers, were commonly used by these men, similarly across all four groups. These results may serve as the background information for better understanding drug-drug interactions during clinical development. 
This study showed that, in contrast to $\mathrm{CaP}$ patients, who had over 2-fold higher all-cause mortality rate than their matched controls, men with elevated PSA but no CaP had a slightly lower mortality rate than their matched controls. This may be explained by the relatively low PSA threshold value we used to define an elevation in PSA level. It may also be a reflection of the complexity of $\mathrm{CaP}$ screening using PSA measurements and the subsequent effect on $\mathrm{CaP}$ mortality, demonstrated in several large randomized studies to be controversial $[18,20,30]$. The cause of death analysis was conducted among patients who consented to the linkage between GPRD and death certificates. Among CaP, about $40 \%$ patients died of reasons other than CaP-specific death. Diseases of circulatory and respiratory systems were important competing risks for $\mathrm{CaP}$ patients and were typical causes of death for all groups of men.

We note several limitations in our study. CaP patients and men with elevated PSA who could not be matched to controls were slightly older than matched cases. Excluding unmatched cases from the analysis could have introduced bias if they differed systematically from those who were matched. However, other baseline demographic factors including smoking status and region of practice were similar between matched and unmatched cases, arguing against substantial bias from this source. Excluding men with $\mathrm{BPH}$ and/or prostatitis from the controls could have magnified case-control differences for comorbidities or medications that are correlated with $\mathrm{BPH}$ or prostatitis. The GPRD is a primary care database and relies on accurate upload of data from the member practices. Data transfer from hospitals to the GPRD can be delayed or missing if GPs do not code and enter the information when they receive it from the hospital. We were unable to explore prevalence and incidence of comorbidities and comedication use by cancer stage and Gleason score because the GPRD lacks these important details. The profile of advanced $\mathrm{CaP}$ patients and early-stage disease patients may well differ with respect to comorbidities and especially medication use, given the indolent nature of the cancer.

Despite these limitations, this study has several strengths. As previously shown [31], the GPRD provides a representative description of patients within the UK. It is a suitable data source for this study, as it is proficient at recording comorbidities and medical care conducted by the GP in primary care. Furthermore, GPRD is an appropriate database especially for studying men with elevated PSA. Per National Institute for Health and Clinical Excellence (NICE) guidance, men with elevated PSA are identified initially in primary care and receive a second test by the GP within 3 months after the initial elevated PSA result. Patients then are referred to a specialist, if the PSA level is elevated again. If $\mathrm{CaP}$ is not diagnosed, patients will return to the care of the GP and be followed within primary care.

\section{Conclusions}

This study provides population-based estimates on the occurrence of comorbidities and medication use among $\mathrm{CaP}$ patients and men with elevated PSA but no CaP. Compared with age-, region- and practice-matched controls who had no
$\mathrm{CaP}$ nor elevated PSA, CaP patients had a higher incidence of urinary tract infection, impotence and breast disorder, and a 2.6-fold higher risk of all-cause mortality. Fewer differences in comorbidities and medication use were noted when men with elevated PSA but no CaP were compared to matched men without elevated PSA nor CaP than were seen between $\mathrm{CaP}$ patients and their matched controls. The mortality rates were slightly lower for men with elevated PSA but no CaP than for matched controls.

Cardiovascular events were similar between $\mathrm{CaP}$ patients and their controls and between men with elevated PSA but no $\mathrm{CaP}$ and their controls. At the time of diagnosis of $\mathrm{CaP}$ or the first occurrence of elevated PSA, many of the most prevalent comorbidities and medications were consistent across groups and are typical of an older male population. As the presence of comorbid conditions and medications places older patients at greater risk of adverse effects from certain interventions, and comorbidity may influence screening practice, treatment choice, quality of life, and survival, these data in the real-world setting are broadly applicable throughout the drug development cycle and subsequent patient management.

\section{Acknowledgments}

The authors wish to thank Dr. Kathleen Beach for clinical consultation, Dr. Nicholas Galwey and Dave Webb for statistical consultation, and Dr. Jon Alsop (WREN group) who undertook the statistical analyses in collaboration with Dr. L. Watson.

\section{References}

[1] J. Ferlay, C. Y. Shin, F. Bray, D. Forman, C. Mathers, and D. M. Parkin, "GLOBOCAN 2008, Cancer Incidence and Mortality Worldwide: IARC Cancer Base No. 10," International Agency for Research on Cancer, Lyon, France, 2010, http:// globocan.iarc.fr.

[2] Cancer Research UK, 2011, http://info.cancerresearchuk.org/ cancerstats/types/prostate/?script=true.

[3] J. W. W. Coebergh, M. L. G. Janssen-Heijnen, P. N. Post, and P. P. A. Razenberg, "Serious co-morbidity among unselected cancer patients newly diagnosed in the southeastern part of The Netherlands in 1993-1996," Journal of Clinical Epidemiology, vol. 52, no. 12, pp. 1131-1136, 1999.

[4] P. L. Marr, E. P. Elkin, S. A. Arredondo, J. M. Broering, J. DuChane, and P. R. Carroll, "Comorbidity and primary treatment for localized prostate cancer: data from CaPSURE," Journal of Urology, vol. 175, no. 4, pp. 1326-1331, 2006.

[5] M. V. Meng, E. P. Elkin, S. R. Harlan, S. S. Mehta, D. P. Lubeck, and P. R. Carroll, "Predictors of treatment after initial surveillance in men with prostate cancer: results from capsure," Journal of Urology, vol. 170, no. 6 I, pp. 2279-2283, 2003.

[6] L. V. Van De Poll-Franse, S. Houterman, M. L. G. JanssenHeijnen, M. W. Dercksen, J. W. W. Coebergh, and H. R. Haak, "Less aggressive treatment and worse overall survival in cancer patients with diabetes: a large population based analysis," International Journal of Cancer, vol. 120, no. 9, pp. 1986-1992, 2007. 
[7] H. I. Hall, W. A. Satariano, T. Thompson, K. E. Ragland, S. K. Van Den Eeden, and S. Selvin, "Initial treatment for prostate carcinoma in relation to comorbidity and symptoms," Cancer, vol. 95, no. 11, pp. 2308-2315, 2002.

[8] S. Houterman, M. L. G. Janssen-Heijnen, A. J. M. Hendrikx, H. A. Van Den Berg, and J. W. W. Coebergh, "Impact of comorbidity on treatment and prognosis of prostate cancer patients: a population-based study," Critical Reviews in Oncology/Hematology, vol. 58, no. 1, pp. 60-67, 2006.

[9] L. C. Harlan, A. Potosky, F. D. Gilliland et al., "Factors associated with initial therapy for clinically localized prostate cancer: prostate cancer outcomes study," Journal of the National Cancer Institute, vol. 93, no. 24, pp. 1864-1871, 2001.

[10] C. B. Begg, E. R. Riedel, P. B. Bach et al., "Variations in morbidity after radical prostatectomy," New England Journal of Medicine, vol. 346, no. 15, pp. 1138-1144, 2002.

[11] M. Froehner, R. Koch, R. Litz, A. Heller, S. Oehlschlaeger, and M. P. Wirth, "Comparison of the American Society of Anesthesiologists Physical Status classification with the Charlson score as predictors of survival after radical prostatectomy," Urology, vol. 62, no. 4, pp. 698-701, 2003.

[12] H. H. Chao, T. Mayer, J. Concato, M. G. Rose, E. Uchio, and W. K. Kelly, "Prostate cancer, comorbidity, and participation in randomized controlled trials of therapy," Journal of Investigative Medicine, vol. 58, no. 3, pp. 566-568, 2010.

[13] I. M. Thompson, D. P. Ankerst, C. Chi et al., "Operating characteristics of prostate-specific antigen in men with an initial PSA level of $3.0 \mathrm{ng} / \mathrm{mL}$ or lower," Journal of the American Medical Association, vol. 294, no. 1, pp. 66-70, 2005.

[14] National Health Service UK, 2011, http://www.cancerscreening.nhs.uk/prostate/index.html.

[15] World Health Organization, "International Statistical Classification of Diseases and Related Health Problems 10th Revision (ICD-10)," 2010, http://apps.who.int/classifications/ icd10/browse/2010/en.

[16] A. Agresti, Categorical Data Analysis, Wiley, Hoboken, NJ, USA, 2nd edition, 2002.

[17] World Health Organization, "International Statistical Classification of Diseases and Related Health Problems 10th Revision (ICD-10)," 2000, http://www.websters-online-dictionary.org/definitions/ICD-10?cx=partner-pub-09394507535297 44\%3Av0qd01-tdlq\&cof=FORID\%3A9\&ie=UTF-8\&q=ICD$10 \& s a=$ Search $\# 906$.

[18] C. D. Berg, G. L. Andriole, E. D. Crawford et al., "Mortality results from a randomized prostate-cancer screening trial," New England Journal of Medicine, vol. 360, no. 13, pp. 13101319, 2009.

[19] F. H. Schröder, M. J. Roobol, G. L. Andriole, and N. Fleshner, "Defining increased future risk for prostate cancer: evidence from a population based screening cohort," Journal of Urology, vol. 181, no. 1, pp. 69-74, 2009.

[20] J. Hugosson, S. Carlsson, G. Aus et al., "Mortality results from the Göteborg randomised population-based prostate-cancer screening trial," The Lancet Oncology, vol. 11, no. 8, pp. 725732, 2010.

[21] H. P. Burden, C. R. Davis, S. Tate, R. Persad, C. H. Holmes, and $\mathrm{K}$. Whittington, "The trends in prostate specific antigen usage amongst United Kingdom urologists—a questionnaire based study," BMC Urology, vol. 8, no. 1, article 17, 2008.

[22] J. Brett, E. Watson, P. Hewitson et al., "PSA testing for prostate cancer: an online survey of the views and reported practice of General Practitioners in the UK," BMC Family Practice, vol. 6, article 24, 2005.
[23] F. Mols, I. J. Korfage, A. J. J. M. Vingerhoets et al., "Bowel, urinary, and sexual problems among long-term prostate cancer survivors: a population-based study," International Journal of Radiation Oncology Biology Physics, vol. 73, no. 1, pp. 30-38, 2009.

[24] E. Ream, A. Quennell, L. Fincham et al., "Supportive care needs of men living with prostate cancer in England: a survey," British Journal of Cancer, vol. 98, no. 12, pp. 1903-1909, 2008.

[25] M. H. Blanker, F. P. M. J. Groeneveld, A. Prins, R. M. D. Bernsen, A. M. Bohnen, and J. L. H. R. Bosch, "Strong effects of definition and nonresponse bias on prevalence rates of clinical benign prostatic hyperplasia: the Krimpen study of male urogenital tract problems and general health status," British Journal of Urology International, vol. 85, no. 6, pp. 665-671, 2000.

[26] R. M. Martin, L. Vatten, D. Gunnell, and P. Romundstad, "Blood pressure and risk of prostate cancer. Cohort Norway (CONOR)," Cancer Causes and Control, vol. 21, no. 3, pp. 463$472,2010$.

[27] A. Altimari, A. D. Grigioni, E. Benedettini et al., "Diagnostic role of circulating free plasma DNA detection in patients with localized prostate cancer," American Journal of Clinical Patho$\log y$, vol. 129, no. 5, pp. 756-762, 2008.

[28] M. Pinkawa, K. Fischedick, B. Gagel et al., "Impact of age and comorbidities on health-related quality of life for patients with prostate cancer: evaluation before a curative treatment," $B M C$ Cancer, vol. 9, article 296, 2009.

[29] R. Yancik, R. J. Havlik, M. N. Wesley et al., "Cancer and comorbidity in older patients: a descriptive profile," Annals of Epidemiology, vol. 6, no. 5, pp. 399-412, 1996.

[30] F. H. Schröder, J. Hugosson, M. J. Roobol et al., "Screening and prostate-cancer mortality in a randomized european study," New England Journal of Medicine, vol. 360, no. 13, pp. 13201328, 2009.

[31] H. Jick, S. S. Jick, and L. E. Derby, "Validation of information recorded on general practitioner based computerised data resource in the United Kingdom," British Medical Journal, vol. 302, no. 6779, pp. 766-768, 1991. 


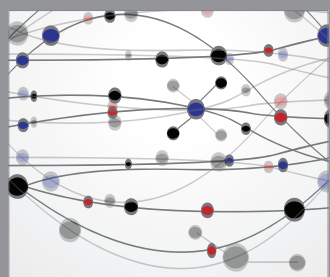

The Scientific World Journal
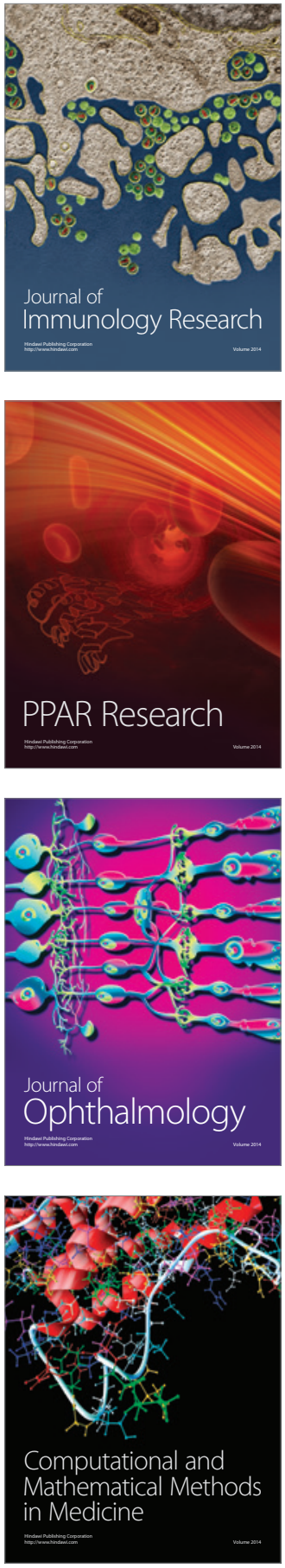

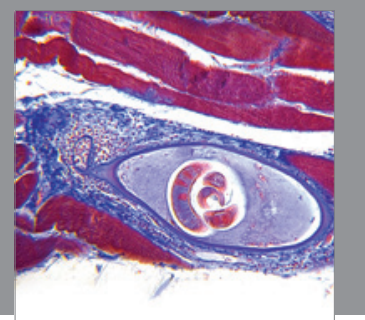

Gastroenterology

Research and Practice
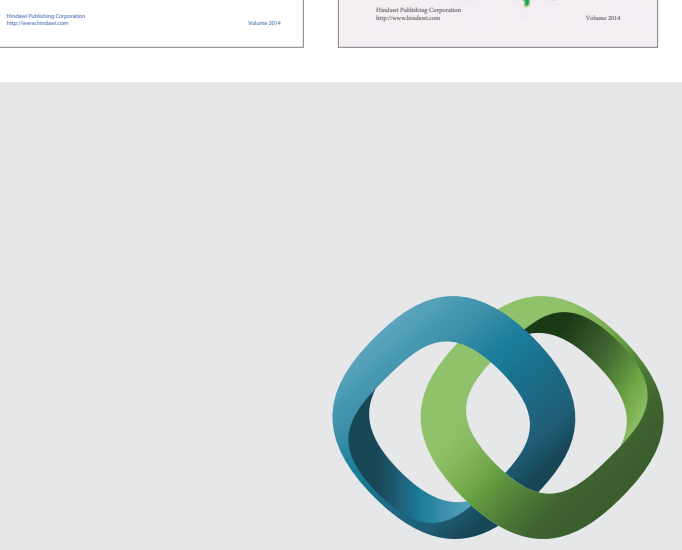

\section{Hindawi}

Submit your manuscripts at

http://www.hindawi.com
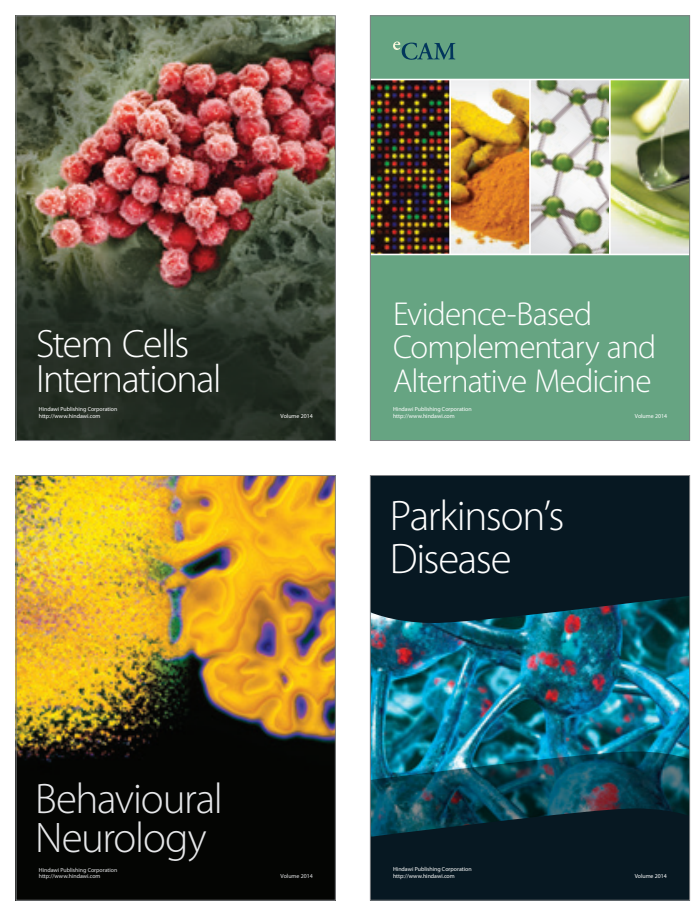

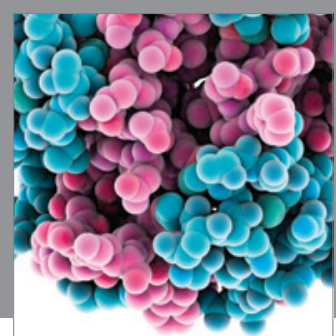

Journal of
Diabetes Research

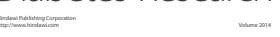

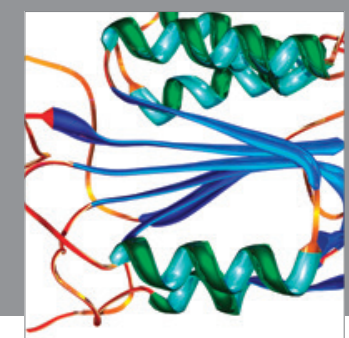

Disease Markers
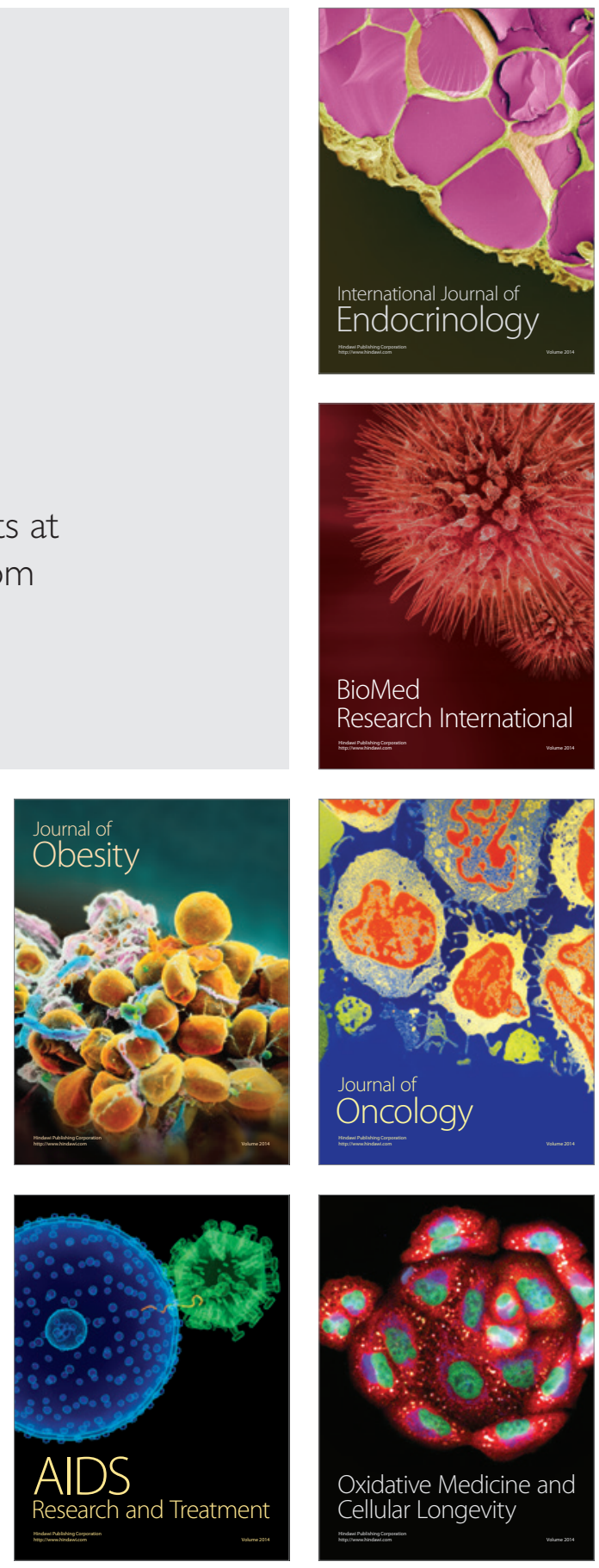